TAO, Vol. 15, No. 5, 839-855, December 2004

\title{
Aerosol Characterization at Taiwan's Northern Tip During Ace-Asia
}

\author{
Cheng-Chuan Wang ${ }^{1}$, Chung-Te Lee ${ }^{1, *}$, Shaw Chen Liu ${ }^{2}$, and Jen-Ping Chen ${ }^{3}$
}

(Manuscript received 14 June 2003, in final form 24 November 2003)

\begin{abstract}
In collaboration with major Pacific Rim countries monitoring transported yellow dust (YD) from East Asia [Aerosol Characterization Experiment in Asia (ACE-Asia)], we made measurements of $\mathbf{P M}_{2.5}$ and $\mathbf{P M}_{10}$ at the Shi-Men site located on Taiwan's northern tip from March to May 2001. Herein we report the results from those measurements.

The average mass concentrations of $P M_{10}$ were 133,103 , and $49 \mu \mathrm{gm}^{-3}$ for April YD, May YD, and non-YD periods, respectively. In contrast, $\mathbf{P M}_{2.5}$ averages for April YD, May YD, and non-YD periods were 41, 49, and $25 \mu \mathrm{gm}^{-3}$, respectively. From the comparisons of particulate matter (PM) mass concentration between YD and non-YD periods, we find an enhancement of 110 and $171 \%$ in $\mathrm{PM}_{10}$ and 64 and $96 \%$ in $\mathrm{PM}_{2.5}$ for the two YD events. The enhancement of water-soluble ions is greater in absolute mass concentration but is significantly less in mass fraction. Since major ions like $\mathrm{NO}_{3}{ }^{-}, \mathrm{NH}_{4}^{+}$and $\mathrm{SO}_{4}{ }^{2-}$ are primarily from anthropogenic sources, their enhancements indicate a significant long-range transport of air pollutants from the Asian Continent to the site.

Ions like $\mathrm{Na}^{+}, \mathrm{Cl}^{-}, \mathrm{Ca}^{2+}$, and $\mathrm{NO}_{3}^{-}$are predominantly distributed in coarse fraction. In contrast, the $\mathrm{NH}_{4}^{+}$and $\mathrm{SO}_{4}{ }^{2-}$ are preferentially distributed in fine fraction. Aerosol carbon is enhanced in mass concentration but not in mass fraction for YD samples, and the ratios of OC/EC for both $\mathbf{P M}_{10}$ and $\mathbf{P M}_{2.5}$ in each YD sample are similar and almost unvaried with PM concentration. By examining aerosol elemental content, we find that elements such, as $\mathrm{Fe}, \mathrm{Ti}, \mathrm{Si}, \mathrm{Ca}, \mathrm{K}$, and $\mathrm{Al}$, are enhanced in $\mathrm{YD}$ samples.
\end{abstract}

${ }^{1}$ Graduate Institute of Environmental Engineering, National Central University, Chung-Li, Taiwan, ROC

2 Research Center for Environmental Changes, Academia Sinica, Taipei, Taiwan, ROC

3 Department of Atmospheric Science, National Taiwan University, Taipei, Taiwan, ROC

* Corresponding author address. Prof. Chung-Te Lee, Graduate Institute of Environmental Engineering, National Central University, Chung-Li, Taiwan, ROC; E-mail: ctlee@cc.ncu.edu.tw 


\begin{abstract}
A method of reconstructed mass shows the resolved mass fractions in $\mathbf{P M}_{10}$ for April average, May average, and non-YD average account for 63,69 , and $72 \%$, respectively and those for $\mathrm{PM}_{2.5}$ are 83,94 , and $91 \%$, respectively. The NOAA HYSPLIT back-trajectory model shows that April YD airflow came from the Gobi Desert in China via a relatively un-polluted inland route, while the May YD airflow transported along the industrial coastal areas in China. This difference in the transport path between April and May dust events may account for the difference in their aerosol compositions.
\end{abstract}

(Key words: ACE-Asia, Aerosol characteristics, Asian dusts, Long-range transport)

\title{
1. INTRODUCTION
}

The occurrence of dust storms in China's northwest Loess Plateau, the Gobi Desert, and Taklamakan Desert in springtime had long been documented in history (Zhang 1984). The transported yellow dust (YD) from a dust storm has a significant influence on the regional energy balance and climate change, visibility reduction, health effects, and on terrestrial and aquatic ecosystems. The dusts transported by the strong air masses deposited easterly in Korea, Japan, North Pacific Ocean, Hawaii, and even in the North America. This phenomenon has drawn significant attention and becomes a focus of international research community (e.g., Xiao et al. 1997; Duce et al. 1980; Parrington et al. 1980).

The influence of YD on Taiwan's air quality can be traced back to April 12 to 15 in 1988 . During that time, levels of $\mathrm{PM}_{10}$ in the southern and the eastern parts of Taiwan were observed to increase dramatically in the range of $201-422 \mu \mathrm{gm}^{-3}$ in different areas. Also, Lin (2001) indicated severe influences on Taiwan's air quality from YD on March 25 and April 28 in 2000 by using a back-trajectory model.

In this work we report findings from our measurements of $\mathrm{PM}_{2.5}$ and $\mathrm{PM}_{10}$ at the ShiMen site, which is located on Taiwan's northern tip, during Aerosol Characterization Experiment in Asia (ACE-Asia) intensive study period from March to May 2001. Aerosol mass concentration, water-soluble ions, carbonaceous content, and elemental content were resolved from the collected filters. A major focus of this work is to examine the differences of aerosol chemical properties between YD and non-YD periods.

\section{METHODS}

\subsection{Sampling Site}

Figure 1 shows the location of the Shi-Men sampling site in northern Taiwan. The site is on a hill $78 \mathrm{~m}$ above the sea level and has no obstruction in the direction of the prevailing northeasterly airflow. Except for a highway extending from west to south, no known pollution source is located in the neighborhood. Under prevailing northeasterly conditions, we expect 


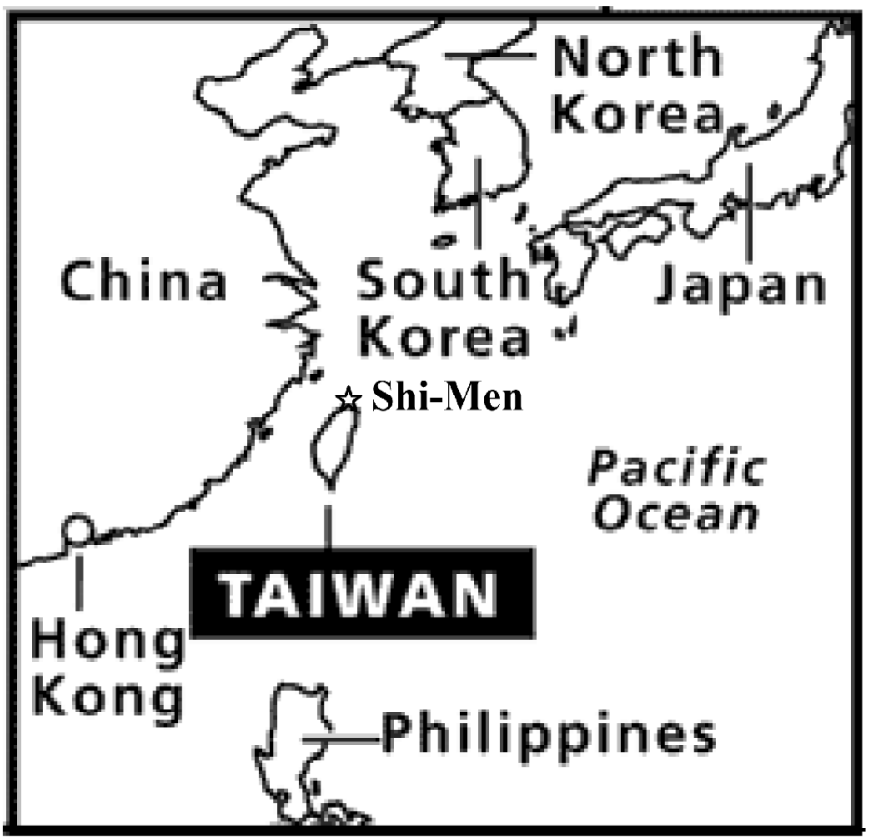

Fig. 1. The location of the Shi-Men sampling site in Taiwan for aerosol collection in ACE-Asia 2001 and the surrounding countries in East Asia.

that the pollutants brought in are from long-range transport.

\subsection{Aerosol Collections and Laboratory Analysis}

The sampler used in this work for aerosol collection was a R\&P model 2300 Partisol Sampler equipped with R\&P ChemComb ${ }^{\circledast}$ Speciation Sampling Cartridges (Rupprecht \& Patashnick Co., Inc., NY, USA). For the analysis of aerosol water-soluble ions, the filter pack was preceded with a coated $\mathrm{ChemComb}^{\circledR}$ denuder to prevent the interference of precursor gases during aerosol collection.

Immediately following the weighing of the filter mass, the collected Teflon ${ }^{\circledR}$ filter was analyzed for elemental compositions using JORDAN VALLEY EX-6600AF energy dispersive X-ray fluorescence (EDXRF) (Jordan Valley, TX, USA). The filter was then ultrasonically extracted for $90 \mathrm{~min}$, into $10 \mathrm{ml}$ of deionized distilled water and filtered through a Teflon ${ }^{\circledR}$ filter with a $0.45 \mu \mathrm{m}$ pore size. This filtrate was injected into an ion chromatograph (DX-120, Dionex Co., Inc., CA, USA) to measure the concentration of water-soluble ions. We sent the quartz filter samples to AtmAA, Inc. (CA, USA) to use the TMO (Thermal Manganese Oxide) method to analyze aerosol carbonaceous content (Muller et al. 1982; Fung 1990). Aerosol 
organic carbon (OC) was determined by heating the samples at $525^{\circ} \mathrm{C}$ for $3 \mathrm{~min}$ in pure $\mathrm{He}$ flow through a flame ionization detector. After the determination of $\mathrm{OC}$, the temperature of the oven was raised to $750^{\circ} \mathrm{C}$ and was exposed to $2.5 \% \mathrm{O}_{2} / \mathrm{He}$ for the detection of elemental carbon (EC). The calibration curve was rechecked every 10 filter samples for quality control purposes.

\section{RESULTS AND DISCUSSION}

\subsection{Aerosol Mass Concentration}

Figure 2 displays time series of $\mathrm{PM}_{10}$ (particulate matter with cut-size $\leq 10 \mu \mathrm{m}$ ) and $\mathrm{PM}_{2.5}$ (particulate matter with cut-size $\leq 2.5 \mu \mathrm{m}$ ) collected from March 23 to May 7, 2001. Two bumps related to two dust events are distinguishable from aerosol mass concentrations of the other periods. The bigger event occurred from April 12 to 14, 2001 and the smaller one dated from May 2 to 3,2001. To show the aerosol mass enhancement (\% increase of aerosol properties) during YD periods, we list in Table 1 aerosol mass concentrations observed in YD and non-YD periods. For non-YD samples, we mean the samples from other than the YD periods. This definition, however, cannot rule out the inclusion of aerosols from long-range transport from China on non-YD days into non-YD samples. The average mass concentrations of $\mathrm{PM}_{10}$ were 133,103 , and $49 \mu \mathrm{gm}^{-3}$ for April YD, May YD, and non-YD periods, respectively. In contrast, $\mathrm{PM}_{2.5}$ averages for April YD, May YD, and non-YD periods were

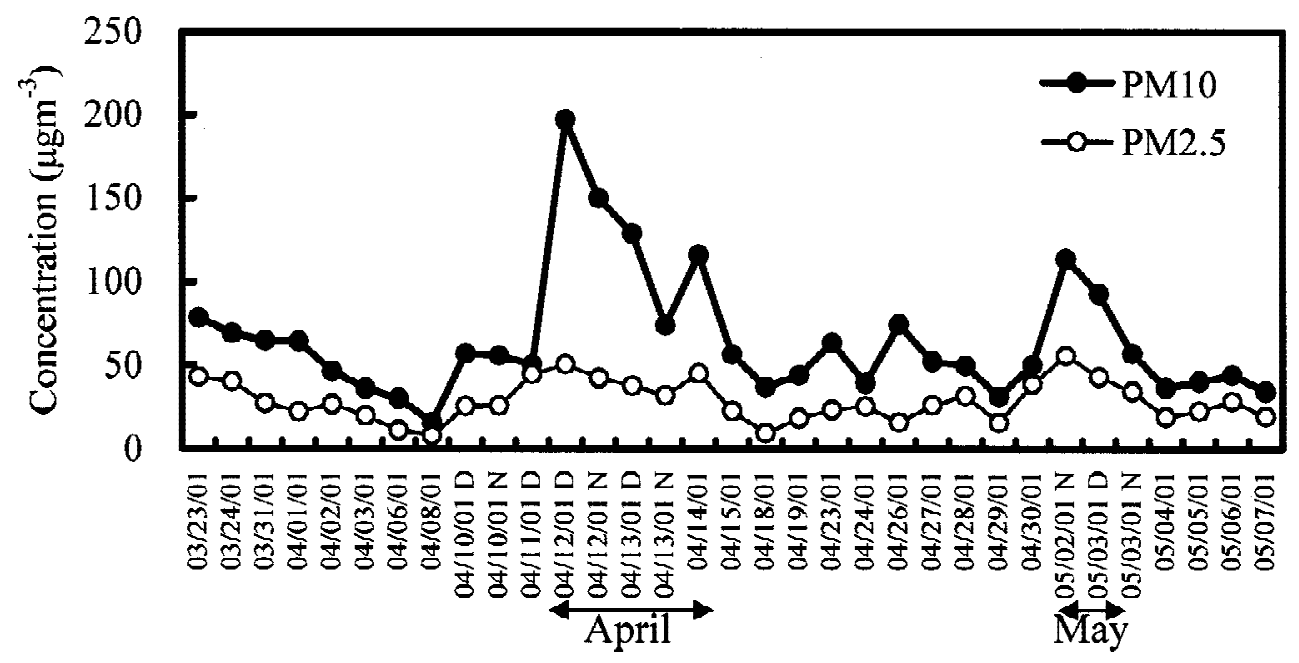

Fig. 2. Time series of $\mathrm{PM}_{10}$ and $\mathrm{PM}_{2.5}$ collected from March 23 to May 7, 2001. The horizontal bars with double-arrow-head indicate the periods for April YD and May YD, respectively. 
Table 1. The mass concentrations $\left(\mu \mathrm{gm}^{-3}\right)$ and the ratios $(\%)$ for different fractions of PM in YD and non-YD periods $(n=26)$.

\begin{tabular}{|c|c|c|c|c|c|}
\hline & $\mathrm{PM}_{2.5}$ & $\mathrm{PM}_{10}$ & $\mathrm{PM}_{10-2.5}{ }^{\#}$ & $\mathrm{PM}_{2.5} / \mathrm{PM}_{10}$ & $\mathrm{PM}_{10-2.5} / \mathrm{PM}_{10}$ \\
\hline $4 / 12 / 01 d^{\$}$ & 50 & 197 & 147 & 26 & 74 \\
\hline $4 / 12 / 01 n^{\$}$ & 42 & 150 & 108 & 28 & 72 \\
\hline $4 / 13 / 01 \mathrm{~d}^{\$}$ & 38 & 129 & 91 & 29 & 71 \\
\hline $4 / 13 / 01 n^{\$}$ & 32 & 74 & 42 & 43 & 57 \\
\hline $4 / 14 / 01^{\$}$ & 45 & 116 & 71 & 39 & 61 \\
\hline April YD* avg. & 41 & 133 & 92 & 33 & 67 \\
\hline $5 / 02 / 01 n^{\$}$ & 56 & 114 & 58 & 49 & 51 \\
\hline $5 / 03 / 01 \mathrm{~d}^{\$}$ & 43 & 93 & 50 & 46 & 54 \\
\hline May YD* avg. & 49 & 103 & 54 & 48 & 52 \\
\hline Non-YD* avg. & 25 & 49 & 24 & 51 & 49 \\
\hline April YD" avg./Non-YD" avg. (4) & 164 & 271 & 383 & 65 & 137 \\
\hline May YD* avg./Non-YD* avg. ${ }^{\text {a }}$ & 196 & 210 & 225 & 94 & 106 \\
\hline
\end{tabular}

\# The concentration of $\mathrm{PM}_{10-2.5}$ is calculated from the difference between $\mathrm{PM}_{10}$ and $\mathrm{PM}_{2.5}$.

\$ The notation of "d" denotes 12-hour collection for daytime period and " $\mathrm{n}$ " for nighttime sample. The sample without "d" or "n" notation shows a 24-hour aerosol collection.

* YD stands for yellow dust.

@ The ratio is in \%.

41, 49, and $25 \mu \mathrm{gm}^{-3}$, respectively. From the comparison of aerosol mass concentrations between YD and non-YD periods, an enhancement of $64 \%$ in $\mathrm{PM}_{2.5}$ for April event and $96 \%$ for May event was observed. For $\mathrm{PM}_{10}$, the enhancement was even greater, reaching $171 \%$ for the April event and $110 \%$ for the May event. If we compare the coarse fraction $\left(\mathrm{PM}_{10-2.5}\right)$ between these two YD events, a more pronounced enhancement of 283\% in April and an enhancement of $125 \%$ in May can be found. This indicates a greater amount of dusts was transported by the airflow in April than that in the May dust storm. As will be discussed in a later section, this contrast was probably due to a difference of the trajectory. 


\subsection{Aerosol Water-soluble Ions}

To obtain an easy comparison for the enhancement of various species in YD periods, we normalize the effect of mass by taking the ratio of each species to its corresponding mass concentration of $\mathrm{PM}_{10}$ or $\mathrm{PM}_{2.5}$. The rationale for this approach is based on the fact that the mass fraction is a better indicator for the characteristics of an emission source than the absolute concentration. The mass fraction of each species during an event can sometimes prevent the masking due to the variation of aerosol mass concentration. For example, the mass concentration $\left(\mu \mathrm{gm}^{-3}\right)$ of a species in YD periods may go up high even without any enhancement in mass fraction, as PM mass concentration is usually high in YD events. To avoid the possible false-negative influence from some species, we display both the normalized (in bold numbers) and absolute values of these species in the following tables. Table 2 shows a comparison for $\mathrm{PM}_{10}$ water-soluble ions between YD and non-YD periods. For all species, enhancements in terms of mass concentrations can be clearly seen in the $\mathrm{YD}$ periods. The $\mathrm{Ca}^{2+}$ is enhanced mostly among all species and is followed by $\mathrm{K}^{+}$. Since $\mathrm{NO}_{3}{ }^{-}, \mathrm{NH}_{4}{ }^{+}$and $\mathrm{SO}_{4}{ }^{2-}$ are major ions and are primarily from anthropogenic sources, their enhancements indicate a significant long-range transport of air pollutants from the Asian Continent to the site. In terms of mass fraction, $\mathrm{Ca}^{2+}$ is enhanced significantly in the April YD event and to a lesser extent in the May event. For $\mathrm{NH}_{4}{ }^{+}$and $\mathrm{SO}_{4}{ }^{2-}$, the enhancements in mass fraction can be seen in the May YD event but not in the April event. This demonstrates a contrast in source contributions in $\mathrm{PM}_{10}$ between the two YD events.

Table 3 shows a similar comparison for $\mathrm{PM}_{2.5}$ water-soluble ions between YD and nonYD periods. $\mathrm{Ca}^{2+}$ and $\mathrm{K}^{+}$are the two species enhanced greatest in both YD events; however, $\mathrm{Ca}^{2+}$ is enhanced to a greater extent in April YD event and $\mathrm{K}^{+}$enhancement is more significant in the May YD event. As in $\mathrm{PM}_{10}$, all species are enhanced in terms of absolute concentration; however, some differences can be found in mass fraction. Among other ions in mass fraction, $\mathrm{Mg}^{2+}, \mathrm{Cl}^{-}$and $\mathrm{NO}_{3}{ }^{-}$are enhanced only in the April YD event and $\mathrm{NH}_{4}{ }^{+}$and $\mathrm{SO}_{4}{ }^{2-}$ are enriched specifically in the May YD event. This again shows that anthropogenic source related species are enhanced in the May YD event.

To compare the ionic distribution in fine $\left(\mathrm{PM}_{2.5}\right)$ and coarse fraction $\left(\mathrm{PM}_{10}-\mathrm{PM}_{2.5}\right)$, we subtract species mass fraction of $\mathrm{PM}_{2.5}$ in Table 3 from that of $\mathrm{PM}_{10}$ in Table 2 (the differences are not shown). Ions like $\mathrm{Na}^{+}, \mathrm{Cl}^{-}, \mathrm{Ca}^{2+}$, and $\mathrm{NO}_{3}{ }^{-}$are predominantly distributed in coarse fraction. In contrast, the $\mathrm{NH}_{4}{ }^{+}$and $\mathrm{SO}_{4}{ }^{2-}$ are significantly distributed in fine fraction. For some ions, the partition between coarse and fine fraction is rather independent of time. For example, the coarse $\mathrm{NO}_{3}{ }^{-}$in $\mathrm{PM}_{10}$ on April, May, and non-YD periods are 81, 79, and 76\%, respectively. In contrast, the calculated fine fraction of $\mathrm{SO}_{4}{ }^{2-}$ in $\mathrm{PM}_{10}$ on April, May, and non-YD periods are 68,85 , and $91 \%$, respectively. Since $\mathrm{SO}_{4}{ }^{2-}$ has been considered produced from photochemical reaction and thus resides in fine fraction, the April dust flow may have $\mathrm{SO}_{2}$ adsorbed onto micron-size dust particles to induce a surface chemical reaction and shifts $\mathrm{SO}_{4}{ }^{2-}$ distribution from fine toward coarse fraction. It is also possible that the coarse $\mathrm{SO}_{4}{ }^{2-}$ is due to the collection of sulfate-containing fine particles by coagulation. 
Table 2. $\mathrm{PM}_{10}\left(\mu \mathrm{gm}^{-3}\right)$, species mass fraction (\%mass in bold number), species concentration $\left(\mu \mathrm{gm}^{-3}\right)$, and ratios (\%) of YD average to non-YD average of water-soluble ions in $\mathrm{PM}_{10}$ in YD and non-YD periods $(\mathrm{n}=26)$.

\begin{tabular}{|c|c|c|c|c|c|c|c|c|c|}
\hline $\mathrm{PM}_{10}$ and $\mathrm{PM}_{10}$ ions ${ }^{\mathrm{z}}$ & $\mathrm{PM}_{10}$ & $\mathrm{Na}^{+}$ & $\mathrm{NH}_{4}^{+}$ & $\mathrm{K}^{+}$ & $\mathrm{Mg}^{2+}$ & $\mathrm{Ca}^{2+}$ & $\mathrm{Cl}^{-}$ & $\mathrm{NO}_{3}^{-}$ & $\mathrm{SO}_{4}{ }^{2-}$ \\
\hline \multirow{2}{*}{$4 / 12 / 01 d^{5}$} & & 3.3 & 1.3 & 0.5 & 0.5 & 3.1 & 5.3 & 2.6 & 8.1 \\
\hline & 197 & 6.5 & 2.5 & 0.9 & 1.0 & 6.1 & 10.5 & 5.1 & 15.9 \\
\hline \multirow{2}{*}{$4 / 12 / 01 n^{\$}$} & & 2.8 & 1.6 & 0.5 & 0.5 & 3.2 & 4.2 & 3.5 & 9.1 \\
\hline & 150 & 4.2 & 2.4 & 0.7 & 0.8 & 4.8 & 6.3 & 5.3 & 13.7 \\
\hline \multirow{2}{*}{$4 / 13 / 01 d^{s}$} & & 2.9 & 2.5 & 0.6 & 0.6 & 2.7 & 4.2 & 4.4 & 10.7 \\
\hline & 129 & 3.7 & 3.3 & 0.7 & 0.8 & 3.5 & 5.4 & 5.7 & 13.8 \\
\hline \multirow{2}{*}{$4 / 13 / 01 n^{s}$} & & 1.0 & 4.9 & 0.7 & 0.3 & 1.7 & 0.6 & 6.2 & 14.3 \\
\hline & 74 & 0.7 & 3.6 & 0.5 & 0.3 & 1.3 & 0.4 & 4.6 & 10.5 \\
\hline \multirow{2}{*}{$4 / 14 / 01^{\$}$} & & 2.5 & 3.0 & 0.9 & 0.6 & 2.0 & 2.6 & 5.5 & 15.0 \\
\hline & 116 & 2.9 & 3.5 & 1.1 & 0.7 & 2.3 & 3.0 & 6.4 & 17.4 \\
\hline \multirow{2}{*}{ April YD* avg. } & & 2.5 & 2.7 & 0.6 & 0.5 & 2.6 & 3.3 & 4.4 & 11.4 \\
\hline & 133 & 3.6 & 3.1 & 0.8 & 0.7 & 3.6 & 5.1 & 5.4 & 14.2 \\
\hline \multirow{2}{*}{$5 / 02 / 01 n^{5}$} & & 2.3 & 6.1 & 1.3 & 0.5 & 1.4 & 1.3 & 3.8 & 23.9 \\
\hline & 114 & 2.6 & 6.9 & 1.5 & 0.5 & 1.6 & 1.5 & 4.3 & 27.1 \\
\hline \multirow{2}{*}{$5 / 03 / 01 d^{s}$} & & 2.4 & 5.2 & 0.7 & 0.5 & 1.2 & 2.3 & 3.7 & 16.8 \\
\hline & 93 & 2.2 & 4.8 & 0.7 & 0.4 & 1.2 & 2.1 & 3.4 & 15.6 \\
\hline \multirow{2}{*}{ May YD* avg. } & & 2.3 & 5.7 & 1.0 & 0.5 & 1.3 & 1.8 & 3.7 & 20.4 \\
\hline & 103 & 2.5 & 5.9 & 1.1 & 0.5 & 1.4 & 1.8 & 3.9 & 21.3 \\
\hline \multirow{2}{*}{ Non-YD* avg. } & & 4.6 & 4.9 & 0.6 & 0.6 & 0.6 & 3.7 & 4.3 & 17.6 \\
\hline & 49 & 2.2 & 2.4 & 0.3 & 0.3 & 0.3 & 1.8 & 2.1 & 8.5 \\
\hline \multirow{2}{*}{ April YD" avg./Non-Y" ${ }^{*}$ avg. ${ }^{*}$} & & 55 & 55 & 103 & 82 & 408 & 92 & 103 & 65 \\
\hline & 271 & 168 & 129 & 264 & 233 & 1120 & 290 & 256 & 167 \\
\hline \multirow{2}{*}{ May YD" avg./Non-YD* avg. ${ }^{\star}{ }^{*}$} & & 51 & 115 & 165 & 76 & 212 & 49 & 87 & 115 \\
\hline & 210 & 111 & 246 & 354 & 165 & 429 & 102 & 182 & 250 \\
\hline
\end{tabular}

$\&$ : In the column for each species, the upper number indicates mass fraction (\% mass in bold number) and the lower number represents its original mass concentration $\left(\mu \mathrm{gm}^{-3}\right)$.

The notations of*, \$, and @ are the same as Table 1. 
Table 3. $\mathrm{PM}_{2.5}\left(\mu \mathrm{gm}^{-3}\right)$, species mass fraction (\% mass in bold number), species concentration $\left(\mu \mathrm{gm}^{-3}\right)$, and ratios (\%) of YD average to non-YD average of water-soluble ions in $\mathrm{PM}_{2.5}$ in YD and non-YD periods $(n=26)$.

\begin{tabular}{|c|c|c|c|c|c|c|c|c|c|}
\hline $\mathrm{PM}_{2.5}$ and $\mathrm{PM}_{2.5}$ ions ${ }^{\mathrm{d}}$ & $\mathrm{PM}_{2.5}$ & $\mathrm{Na}^{+}$ & $\mathrm{NH}_{4}^{+}$ & $\mathrm{K}^{+}$ & $\mathrm{Mg}^{2+}$ & $\mathrm{Ca}^{2+}$ & $\mathrm{Cl}^{-}$ & $\mathrm{NO}_{3}^{-}$ & $\mathrm{SO}_{4}{ }^{2}$ \\
\hline \multirow{2}{*}{$4 / 12 / 01 d^{\$}$} & & 1.4 & 4.1 & 1.0 & 0.4 & 1.6 & 1.1 & 2.9 & 15.3 \\
\hline & 50 & 0.7 & 2.1 & 0.5 & 0.2 & 0.8 & 0.6 & 1.5 & 7.7 \\
\hline \multirow{2}{*}{$4 / 12 / 01 n^{\$}$} & & 1.1 & 6.2 & 1.1 & 0.4 & 2.0 & 0.6 & 2.8 & 21.7 \\
\hline & 42 & 0.5 & 2.6 & 0.5 & 0.2 & 0.8 & 0.3 & 1.2 & 9.2 \\
\hline \multirow{2}{*}{$4 / 13 / 01 d^{\$}$} & & 0.9 & 7.8 & 1.1 & 0.3 & 1.2 & 0.7 & 2.6 & 23.8 \\
\hline & 38 & 0.3 & 3.0 & 0.4 & 0.1 & 0.5 & 0.3 & 1.0 & 9.0 \\
\hline \multirow{2}{*}{$4 / 13 / 01 n^{\$}$} & & 0.4 & 10.1 & 1.1 & 0.2 & 0.6 & 0.4 & 2.8 & 27.1 \\
\hline & 32 & 0.1 & 3.2 & 0.4 & 0.1 & 0.2 & 0.1 & 0.9 & 8.6 \\
\hline \multirow{2}{*}{$4 / 14 / 01^{\$}$} & & 0.9 & 8.0 & 1.9 & 0.3 & 0.8 & 0.3 & 1.4 & 29.6 \\
\hline & 45 & 0.4 & 3.6 & 0.9 & 0.1 & 0.3 & 0.1 & 0.6 & 13.3 \\
\hline \multirow{2}{*}{ April YD* avg. } & & 0.9 & 7.2 & 1.2 & 0.3 & 1.2 & 0.6 & 2.5 & 23.5 \\
\hline & 41 & 0.4 & 2.9 & 0.5 & 0.1 & 0.5 & 0.3 & 1.0 & 9.6 \\
\hline \multirow{2}{*}{$5 / 02 / 01 n^{\$}$} & & 0.5 & 12.6 & 2.0 & 0.1 & 0.3 & 0.3 & 1.2 & 40.4 \\
\hline & 56 & 0.3 & 7.0 & 1.1 & 0.1 & 0.2 & 0.2 & 0.7 & 22.5 \\
\hline \multirow{2}{*}{$5 / 03 / 01 d^{\$}$} & & 0.7 & 11.7 & 1.2 & 0.2 & 0.4 & 0.5 & 2.0 & 32.4 \\
\hline & 43 & 0.3 & 5.0 & 0.5 & 0.1 & 0.2 & 0.2 & 0.9 & 13.9 \\
\hline \multirow{2}{*}{ May YD* avg. } & & 0.6 & 12.1 & 1.6 & 0.2 & 0.4 & 0.4 & 1.6 & 36.4 \\
\hline & 49 & 0.3 & 6.0 & 0.8 & 0.1 & 0.2 & 0.2 & 0.8 & 18.2 \\
\hline \multirow{2}{*}{ Non-YD ${ }^{*}$ avg. } & & 1.4 & 10.1 & 0.7 & 0.2 & 0.2 & 0.6 & 2.2 & 30.0 \\
\hline & 25 & 0.3 & 2.6 & 0.2 & 0.04 & 0.05 & 0.1 & 0.5 & 7.7 \\
\hline \multirow{2}{*}{ April YD ${ }^{*}$ avg. $/$ Non-YD ${ }^{*}$ avg. ${ }^{@}$} & & 66 & 71 & 179 & 152 & 510 & 104 & 112 & 79 \\
\hline & 164 & 132 & 110 & 295 & 294 & 1037 & 222 & 207 & 124 \\
\hline \multirow{2}{*}{ May YD* avg./Non-YD* avg. ${ }^{\circledR}$} & & 44 & 120 & 229 & 82 & 161 & 66 & 71 & 122 \\
\hline & 196 & 99 & 230 & 461 & 178 & 372 & 154 & 154 & 236 \\
\hline
\end{tabular}

The notations of $\&$ is the same as Table2 and *, \$, and @ are the same as Table 1. 


\subsection{Aerosol Carbonaceous Content}

The PM concentration, mass fraction (\% mass in bold number) and mass concentration $\left(\mu \mathrm{gm}^{-3}\right)$ of carbonaceous content, and ratios of $\mathrm{OC} / \mathrm{EC}$ in $\mathrm{PM}_{10}$ and $\mathrm{PM}_{2.5}$ in YD and nonYD periods $(n=25)$ are shown in Table 4. Although the mass concentrations from YD averages are greater than those of non-YD average, the differences of aerosol carbon are not strikingly much. Looking into the mass fraction ratio of YD average to non-YD average, we find the fraction of carbon content is even lower in YD periods. This indicates that the airflow did not transport a proportional aerosol carbon as it did with such water-soluble ions in YD periods. This may imply that aerosol carbons are not distributed in a broad area as are water-soluble ions. Table 4 also shows greater mass fractions and mass concentrations of OC and EC in $\mathrm{PM}_{2.5}$ than those in $\mathrm{PM}_{10}$. Interestingly, the ratios of $\mathrm{OC} / \mathrm{EC}$ for $\mathrm{PM}_{10}$ and $\mathrm{PM}_{2.5}$ in each YD periods are similar and almost unvaried with $\mathrm{PM}$ concentration. This feature represents a stable $\mathrm{OC} / \mathrm{EC}$ ratio in coarse and fine particles for the same YD run. However, aerosol carbon content and OC/EC ratio are still different for the April YD, May YD, and non-YD periods. It is noted that the April YD event has a greater EC content and lower OC content than that in the May YD event. Since part of OC was related to atmospheric photochemical reaction, we conjectured that less precursor gases were mixed in the transported airflow in April YD event and the airflow in May YD event passed along an area with more precursor gases. This inference can be justified later in back-trajectory analysis.

\subsection{Aerosol Elemental Content}

Table 5 shows $\mathrm{PM}_{10}\left(\mu \mathrm{gm}^{-3}\right)$, mass fraction (\% mass in bold number) and mass concentration $\left(\mu \mathrm{gm}^{-3}\right)$ of elemental content, and ratios of YD average to non-YD average of elemental content in $\mathrm{PM}_{10}$ both in $\mathrm{YD}$ and non-YD periods $(\mathrm{n}=26)$. By examining the mass fraction and mass concentration ratio of $\mathrm{YD}$ average to non-YD average for each element in $\mathrm{PM}_{10}$, we find elements $\mathrm{Fe}, \mathrm{Ti}, \mathrm{Si}, \mathrm{K}, \mathrm{Ca}$, and $\mathrm{Al}$ are enhanced in YD periods. The sulfur content is enhanced in terms of mass concentration but not enhanced in the mass fraction of $\mathrm{PM}_{10}$ in $\mathrm{YD}$ periods. For those elements enhanced in YD periods, the enhancement is less in May than that in April. Table 6 displays the $\mathrm{PM}_{2.5}\left(\mu \mathrm{gm}^{-3}\right)$, mass fraction (\% mass in bold number) and mass concentration $\left(\mu \mathrm{gm}^{-3}\right)$ of elemental content, and ratios of YD average to non-YD average of elemental content in $\mathrm{PM}_{2.5}$ both in YD and non-YD periods $(\mathrm{n}=26)$. The enhancement of elements is quite similar to that in $\mathrm{PM}_{10}$ except for sulfur, which is greatly enhanced in the May YD periods. Elements like $\mathrm{Fe}, \mathrm{Ti}, \mathrm{Si}$, and $\mathrm{Ca}$ are consistently distributed more in coarse fraction in YD periods. The sulfur element is significantly distributed in the fine fraction for YD and non-YD periods.

\subsection{Reconstructed Aerosol Mass}

In evaluating the completeness of the resolved aerosol composition, a method of mass reconstruction was adopted to convert aerosol species into their likely compound forms and compare with the gravimetric mass. Table 7 lists the measured species, the conversion factors 
Table 4. The PM concentration, mass fraction (\% mass in bold number) of carbonaceous content, mass concentration $\left(\mu \mathrm{gm}^{-3}\right)$ of carbonaceous content, ratios (\%) of OC/EC, and ratios (\%) of YD average to non-YD average in $\mathrm{PM}_{10}$ and $\mathrm{PM}_{2.5}$ in $\mathrm{YD}$ and non-YD periods $(\mathrm{n}=25)$.

\begin{tabular}{|c|c|c|c|c|c|c|c|c|}
\hline PM and PM carbons & $\mathrm{PM}_{10}$ & $\mathrm{PM}_{2.5}$ & $\begin{array}{c}\mathrm{PM}_{10} \\
\mathrm{EC}\end{array}$ & $\begin{array}{c}\mathrm{PM}_{10} \\
\mathrm{OC}\end{array}$ & $\begin{array}{c}\mathrm{PM}_{10} \\
\mathrm{OC} / \mathrm{EC}\end{array}$ & $\begin{array}{c}\mathrm{PM}_{2.5} \\
\mathrm{EC}\end{array}$ & $\begin{array}{c}\mathrm{PM}_{2.5} \\
\mathrm{OC}\end{array}$ & $\begin{array}{c}\mathrm{PM}_{2.5} \\
\mathrm{OC} / \mathrm{EC}\end{array}$ \\
\hline \multirow{2}{*}{$4 / 12 / 01 d^{\$}$} & & & 1.2 & 2.2 & 190 & 3.2 & 5.6 & 177 \\
\hline & 197 & 50 & 2.3 & 4.3 & 190 & 1.6 & 2.8 & 177 \\
\hline \multirow{2}{*}{$4 / 12 / 01 n^{S}$} & & & 1.1 & 2.7 & 246 & 2.5 & 5.6 & 228 \\
\hline & 150 & 42 & 1.7 & 4.1 & 246 & 1.0 & 2.4 & 228 \\
\hline \multirow{2}{*}{$4 / 13 / 01 d^{\$}$} & & & 1.2 & 2.4 & 200 & 3.2 & 5.7 & 182 \\
\hline & 129 & 38 & 1.6 & 3.1 & 200 & 1.2 & 2.2 & 182 \\
\hline \multirow{2}{*}{$4 / 13 / 01 n^{\$}$} & & & 3.1 & 7.9 & 253 & 6.5 & 17.7 & 272 \\
\hline & 74 & 32 & 2.3 & 5.8 & 253 & 2.1 & 5.7 & 272 \\
\hline \multirow{2}{*}{$4 / 14 / 01^{\$}$} & & & 2.5 & 4.6 & 182 & 4.8 & 8.3 & 172 \\
\hline & 116 & 45 & 2.9 & 5.4 & 182 & 2.2 & 3.7 & 172 \\
\hline \multirow{2}{*}{ April YD" avg. } & & & 1.8 & 4.0 & 214 & 4.0 & 8.6 & 206 \\
\hline & 133 & 41 & 2.1 & 4.5 & 214 & 1.6 & 3.5 & 206 \\
\hline \multirow{2}{*}{$5 / 02 / 01 n^{\$}$} & & & 1.2 & 5.9 & 480 & 2.3 & 10.6 & 450 \\
\hline & 114 & 56 & 1.4 & 6.7 & 480 & 1.3 & 5.9 & 450 \\
\hline \multirow{2}{*}{$5 / 03 / 01 d^{S}$} & & & 1.3 & 6.2 & 485 & 2.9 & 11.9 & 408 \\
\hline & 93 & 43 & 1.2 & 5.8 & 485 & 1.3 & 5.1 & 408 \\
\hline \multirow{2}{*}{ May YD* avg. } & & & 1.3 & 6.1 & 482 & 2.6 & 11.2 & 429 \\
\hline & 103 & 49 & 1.3 & 6.3 & 482 & 1.3 & 5.5 & 429 \\
\hline \multirow{2}{*}{ Non-YD avg. } & & & 2.3 & 8.7 & 411 & 3.7 & 13.2 & 356 \\
\hline & 49 & 25 & 1.1 & 4.3 & 411 & 0.9 & 3.3 & 356 \\
\hline \multirow{2}{*}{ April YD" avg./Non-YD" avg. ${ }^{\oplus}$} & & & 80 & 46 & 52 & 107 & 65 & 58 \\
\hline & 271 & 164 & 218 & 123 & 52 & 177 & 107 & 58 \\
\hline \multirow{2}{*}{ May $\mathrm{YD}^{*}$ avg./Non-YD* avg. } & & & 55 & $\mathbf{7 0}$ & 117 & 70 & 85 & 120 \\
\hline & 210 & 196 & 118 & 147 & 117 & 138 & 166 & 120 \\
\hline
\end{tabular}

The notations of *, \$, and @ are the same as Table 1. 
Table 5. $\mathrm{PM}_{10}\left(\mu \mathrm{gm}^{-3}\right)$, mass fraction (\% mass in bold number) of elemental content, mass concentration $\left(\mu \mathrm{gm}^{-3}\right)$ of elemental content, and ratios $(\%)$ of $\mathrm{YD}$ average to non-YD average in $\mathrm{PM}_{10}$ in $\mathrm{YD}$ and non-YD periods $(n=26)$.

\begin{tabular}{|c|c|c|c|c|c|c|c|c|c|c|}
\hline $\mathrm{PM}_{10}$ and $\mathrm{PM}_{10}$ elements & $\mathrm{PM}_{10}$ & $\mathrm{Fe}$ & $\mathrm{Ti}$ & $\mathrm{Si}$ & $S$ & $\mathrm{Cl}$ & $\mathrm{K}$ & $\mathrm{Ca}$ & $\mathrm{Na}$ & $\mathrm{Al}$ \\
\hline \multirow{2}{*}{$4 / 12 / 01 d^{\$}$} & & 1.7 & 0.13 & 5.7 & 1.5 & 2.6 & 1.1 & 2.6 & 4.6 & 4.1 \\
\hline & 197 & 3.3 & 0.25 & 11.2 & 3.0 & 5.1 & 2.2 & 5.1 & 9.1 & 8.1 \\
\hline \multirow{2}{*}{$4 / 12 / 01 n^{\$}$} & & 1.1 & 0.08 & 3.7 & 1.2 & 1.5 & 0.7 & 1.6 & 3.3 & 2.7 \\
\hline & 150 & 1.7 & 0.12 & 5.6 & 1.8 & 2.3 & 1.1 & 2.4 & 5.0 & 4.1 \\
\hline \multirow{2}{*}{$4 / 13 / 01 d^{\$}$} & & 2 & 0.17 & 7.4 & 3.2 & 3.3 & 1.4 & 2.7 & 5.9 & 5.3 \\
\hline & 129 & 2.6 & 0.22 & 9.5 & 4.1 & 4.3 & 1.8 & 3.5 & 7.6 & 6.8 \\
\hline \multirow{2}{*}{$4 / 13 / 01 n^{\$}$} & & 1.3 & 0.11 & 4.3 & 3.1 & 0.3 & 1 & 1.4 & 4.6 & 5.2 \\
\hline & 74 & 1.0 & 0.08 & 3.2 & 2.3 & 0.2 & 0.7 & 1.0 & 3.4 & 3.8 \\
\hline \multirow{2}{*}{$4 / 14 / 01^{\$}$} & & 1.5 & 0.12 & 4.5 & 3.3 & 1.7 & 1.3 & 1.6 & 3.4 & 3.5 \\
\hline & 116 & 1.7 & 0.14 & 5.2 & 3.8 & 2.0 & 1.5 & 1.9 & 3.9 & 4.1 \\
\hline \multirow{2}{*}{ April YD* avg. } & & 1.5 & 0.12 & 5.1 & 2.5 & 1.1 & 1.1 & 2 & 4.4 & 4.2 \\
\hline & 133 & 2.0 & 0.16 & 6.8 & 3.3 & 1.5 & 1.5 & 2.7 & 5.9 & 5.6 \\
\hline \multirow{2}{*}{$5 / 02 / 01 n^{\$}$} & & 0.9 & 0.07 & 2.9 & 5 & 0.8 & 1.1 & 1 & 4.4 & 3 \\
\hline & 114 & 1.0 & 0.08 & 3.3 & 5.7 & 0.9 & 1.3 & 1.1 & 5.0 & 3.4 \\
\hline \multirow{2}{*}{$5 / 03 / 01 d^{\$}$} & & 1.1 & 0.10 & 3.6 & 3.8 & 1.4 & 1 & 1.1 & 5.3 & 4.9 \\
\hline & 93 & 1.0 & 0.09 & 3.3 & 3.5 & 1.3 & 0.9 & 1.0 & 4.9 & 4.6 \\
\hline \multirow{2}{*}{ May YD" avg. } & & 1 & 0.09 & 3.2 & 4.4 & 1.1 & 1 & 1.1 & 4.9 & 3.9 \\
\hline & 103 & 1.0 & 0.09 & 3.3 & 4.5 & 1.1 & 1.0 & 1.1 & 5.0 & 4.0 \\
\hline \multirow{2}{*}{ Non-YD" avg. } & & 0.5 & 0.06 & 2.1 & 4.5 & 2.8 & 0.6 & 0.7 & 7.9 & 3.4 \\
\hline & 49 & 0.2 & 0.03 & 1.0 & 2.2 & 1.4 & 0.3 & 0.3 & 3.9 & 1.7 \\
\hline \multirow{2}{*}{ April YD" avg./Non-YD" avg. ${ }^{\circledR}$} & & 281 & 200 & 242 & 54 & 66 & 179 & 294 & 55 & 123 \\
\hline & 271 & 814 & 533 & 659 & 151 & 107 & 498 & 776 & 151 & 335 \\
\hline \multirow{2}{*}{ May $\mathrm{YD}^{*}$ avg./Non-YD* avg. ${ }^{*}$} & & 180 & 150 & 153 & 97 & 39 & 171 & 158 & 61 & 116 \\
\hline & 210 & 420 & 300 & 320 & 206 & 83 & 350 & 330 & 130 & 241 \\
\hline
\end{tabular}

The notations of*, \$, and @ are the same as Table 1. 
Table 6. $\mathrm{PM}_{2.5}\left(\mu \mathrm{gm}^{-3}\right)$, mass fraction (\% mass in bold number) of elemental content, mass concentration $\left(\mu \mathrm{gm}^{-3}\right)$ of elemental content, and ratios $(\%)$ of YD average to non-YD average in $\mathrm{PM}_{10}$ in YD and non-YD periods $(n=26)$.

\begin{tabular}{|c|c|c|c|c|c|c|c|c|c|c|}
\hline $\mathrm{PM}_{2.5}$ and $\mathrm{PM}_{2.5}$ elements & $\mathrm{PM}_{2.5}$ & $\mathrm{Fe}$ & $\mathrm{Ti}$ & $\mathrm{Si}$ & $\mathrm{S}$ & $\mathrm{Cl}$ & $\mathrm{K}$ & $\mathrm{Ca}$ & $\mathrm{Na}$ & $\mathrm{Al}$ \\
\hline \multirow{2}{*}{$4 / 12 / 01 d^{S}$} & & 1.1 & 0.08 & 2.8 & 2.8 & 0.5 & 1.2 & 1.3 & 15 & 7 \\
\hline & 50 & 0.6 & 0.04 & 1.4 & 1.4 & 0.3 & 0.6 & 0.7 & 7.5 & 3.5 \\
\hline \multirow{2}{*}{$4 / 12 / 01 n^{\$}$} & & 1.1 & 0.10 & 4.5 & 3.6 & 0.3 & 1.3 & 1.4 & 9.7 & 7 \\
\hline & 42 & 0.5 & 0.04 & 1.9 & 1.5 & 0.1 & 0.6 & 0.6 & 4.1 & 2.9 \\
\hline \multirow{2}{*}{$4 / 13 / 01 d^{s}$} & & 1.2 & 0.12 & 4.3 & 5.6 & 0.3 & 1.5 & 1.2 & 16.1 & 10 \\
\hline & 38 & 0.4 & 0.05 & 1.6 & 2.1 & 0.1 & 0.5 & 0.5 & 6.1 & 3.8 \\
\hline \multirow{2}{*}{$4 / 13 / 01 n^{\$}$} & & 0.8 & 0.07 & 2.9 & 6.4 & 0.2 & 1.1 & 0.9 & 17.1 & 6.8 \\
\hline & 32 & 0.3 & 0.02 & 0.9 & 2.0 & 0.1 & 0.4 & 0.3 & 5.5 & 2.2 \\
\hline \multirow{2}{*}{$4 / 14 / 01^{s}$} & & 0.6 & 0.05 & 2.1 & 4.7 & 0.1 & 1.2 & 0.5 & 5.8 & 3.6 \\
\hline & 45 & 0.3 & 0.02 & 0.9 & 2.1 & 0.0 & 0.5 & 0.2 & 2.6 & 1.6 \\
\hline \multirow{2}{*}{ April YD* avg. } & & 1 & 0.08 & 3.3 & 4.6 & 0.3 & 1.3 & 1.1 & 12.7 & 6.9 \\
\hline & 41 & 0.4 & 0.03 & 1.4 & 1.8 & 0.1 & 0.5 & 0.4 & 5.2 & 2.8 \\
\hline \multirow{2}{*}{$5 / 02 / 01 n^{\$}$} & & 0.5 & 0.02 & 1.8 & 8.6 & 0.1 & 1.5 & 0.4 & 8.5 & 3.9 \\
\hline & 56 & 0.3 & 0.01 & 1.0 & 4.8 & 0.1 & 0.8 & 0.2 & 4.7 & 2.2 \\
\hline \multirow{2}{*}{$5 / 03 / 01 d^{\$}$} & & 0.7 & 0.04 & 3.7 & 6.5 & 0.2 & 1.1 & 0.6 & 14 & 6.8 \\
\hline & 43 & 0.3 & 0.02 & 1.6 & 2.8 & 0.1 & 0.5 & 0.3 & 6.0 & 2.9 \\
\hline \multirow{2}{*}{ May YD" avg. } & & 0.6 & 0.03 & 2.7 & 7.6 & 0.2 & 1.3 & 0.5 & 11.2 & 5.4 \\
\hline & 49 & 0.3 & 0.02 & 1.3 & 3.8 & 0.1 & 0.6 & 0.3 & 5.4 & 2.6 \\
\hline \multirow{2}{*}{ Non-YD" avg. } & & 0.4 & 0.03 & 1.8 & 6.9 & 0.3 & 0.6 & 0.5 & 13.6 & 5.7 \\
\hline & 25 & 0.1 & 0.01 & 0.4 & 1.7 & 0.1 & 0.1 & 0.1 & 2.9 & 1.2 \\
\hline \multirow{2}{*}{ April $Y^{*}{ }^{*}$ avg./Non-YD* avg. } & & 246 & 273 & 188 & 67 & 101 & 197 & 243 & 94 & 122 \\
\hline & 164 & 476 & 563 & 353 & 107 & 214 & 358 & 492 & 181 & 241 \\
\hline \multirow{2}{*}{ May YD* avg./Non-YD* avg. ${ }^{*}$} & & 151 & 113 & 154 & 110 & 59 & 199 & 121 & 83 & 95 \\
\hline & 196 & 336 & 267 & 333 & 222 & 141 & 439 & 282 & 188 & 220 \\
\hline
\end{tabular}

The notations of *, \$, and @ are the same as Table 1. 
and their assumed compound forms. For carbonaceous content, the organic carbon is considered to be in organic matter and the conversion factor is assumed as 1.4 (Turpin et al. 1997). The water-soluble ions were kept in ionic forms except $\mathrm{Cl}^{-}$, which was assumed to be equal in moles to $\mathrm{Na}^{+}$as the underestimation of chloride was considered due to chlorine loss effect in the atmosphere (Ohta and Okita 1990). The resolved elements were considered to be in their oxide states in the mass reconstruction calculation.

Table 7. Measured aerosol species and the conversion factor into its assumed compound form for mass reconstruction.

\begin{tabular}{|c|c|c|}
\hline Measured species & Assumed compound form & Mass conversion factor \\
\hline $\mathrm{Br}$ & $\left(\mathrm{CH}_{2} \mathrm{Br}\right)_{2}$ & 1.175 \\
\hline $\mathrm{Pb}$ & $\mathrm{PbO}$ & 1.077 \\
\hline $\mathrm{Mn}$ & $\mathrm{MnO}$ & 1.291 \\
\hline $\mathrm{Fe}$ & $\mathrm{Fe}_{2} \mathrm{O}_{3}$ & 1.429 \\
\hline $\mathrm{Cu}$ & $\mathrm{CuO}$ & 1.254 \\
\hline $\mathrm{Ni}$ & $\mathrm{NiO}$ & 1.271 \\
\hline $\mathrm{Zn}$ & $\mathrm{ZnO}$ & 1.246 \\
\hline $\mathrm{Ti}$ & $\mathrm{TiO}_{2}$ & 1.667 \\
\hline $\mathrm{V}$ & $\mathrm{V}_{2} \mathrm{O}_{5}$ & 1.784 \\
\hline $\mathrm{Si}$ & $\mathrm{SiO}_{2}$ & 2.143 \\
\hline $\mathrm{K}$ & $\mathrm{K}_{2} \mathrm{O}_{3}$ & 1.769 \\
\hline $\mathrm{Ca}$ & $\mathrm{CaCO}_{3}$ & 2.5 \\
\hline $\mathrm{Mg}$ & $\mathrm{MgO}$ & 1.667 \\
\hline $\mathrm{A} 1$ & $\mathrm{Al}_{2} \mathrm{O}_{3}$ & 1.889 \\
\hline $\mathrm{Na}^{+}$ & $\mathrm{NaCl}$ & 2.54 \\
\hline $\mathrm{NH}_{4}^{+}$ & $\mathrm{NH}_{4}^{+}$ & 1 \\
\hline $\mathrm{SO}_{4}{ }^{2-}$ & $\mathrm{SO}_{4}{ }^{2-}$ & 1 \\
\hline $\mathrm{NO}_{3}^{-}$ & $\mathrm{NO}_{3}^{-}$ & 1 \\
\hline $\mathrm{PO}_{4}{ }^{3-}$ & $\mathrm{PO}_{4}{ }^{3-}$ & 1 \\
\hline $\mathrm{F}^{-}$ & $\mathrm{F}^{-}$ & 1 \\
\hline $\mathrm{OC}$ & Organic Matter (OM) & 1.4 \\
\hline $\mathrm{EC}$ & Soot & 1.0 \\
\hline
\end{tabular}


Table 8 shows the reconstructed mass fraction for $\mathrm{PM}_{10}$ and $\mathrm{PM}_{2.5}$ by compound categories in YD and non-YD periods. For a comparison of the resolved compound categories between YD and non-YD periods, we find the resolved mass fractions of water-soluble ions and carbonaceous content are greater and those of elemental oxides are lower on non-YD period both in $\mathrm{PM}_{10}$ and $\mathrm{PM}_{2.5}$. Also, there is more unresolved mass fraction in $\mathrm{PM}_{10}$ than that in $\mathrm{PM}_{2.5}$, which implies more coarse fraction is unidentified. The unresolved fractions of the reconstructed masses were probably due to the unanalyzed aerosol species, such as metals and organics on the collected filter. Among three resolved compound categories, water-soluble ions is the category with the greatest identified mass fraction, except for $\mathrm{PM}_{10}$ in the April YD period. Furthermore, we find that the resolved percentage of aerosol mass in the May YD period is greater than that in the April YD period. Similar to the comparison between non-YD and YD periods, the May YD period had greater resolved mass fractions of water-soluble ions and carbonaceous content and lower elemental oxides than did the April YD period. This indicates that the aerosol composition in May YD period is closer to that in non-YD period than it is in the April YD period.

\subsection{Back-trajectory Analysis}

As discussed above, we found a significant difference in aerosol properties between the April YD and the May YD periods. This is likely the result of a difference in aerosol transport paths. To derive the air trajectory arriving at the sampling site, the Hybrid Single-Particle Lagrangian Integrated Trajectories (HYSPLIT) model (Draxler 1999) developed by US NOAA Air Resources Laboratory is adopted in this work. The input parameters include the longitude and latitude of the sampling site $(25.28 \mathrm{~N}, 121.58 \mathrm{E})$, arrival time, hours traced back (72 hours), and the heights of air trajectories (200 and $500 \mathrm{~m}$ ).

Figure 3 shows the backward air trajectory for the night of April 12, 2001. It could be seen that the 72-hour back-trajectories for the arrived heights at $200 \mathrm{~m}$ and $500 \mathrm{~m}$ were both originated from the Gobi Desert and were transported significantly above $1000 \mathrm{~m}$ (the typical depth of planetary boundary layer) most of the time. In contrast, Figure 4 showed that the trajectory for $200 \mathrm{~m}$ in the morning of May 3, 2001 had passed through China's major industrial coastal areas and was transported below $1000 \mathrm{~m}$ in altitude. Consequently, the air mass of the May dust event had a better chance of picking up pollutants from the ground. This distinction in the transport paths of the April and May dust events may well account for the observed difference in the aerosol compositions.

\section{SUMMARY}

In collaboration with international ACE-Asia intensive field experiment, we made measurements of $\mathrm{PM}_{2.5}$ and $\mathrm{PM}_{10}$ at the Shi-Men site located on Taiwan's northern tip from March to May 2001. Two major YD events, one in April and the other in May in 2001, were observed. We have examined aerosol chemical properties of the two YD events and compared them with those of non-YD periods. 
Table 8. Reconstructed mass fraction (\%) for $\mathrm{PM}_{10}\left(\mu \mathrm{gm}^{-3}\right)$ and $\mathrm{PM}_{2.5}\left(\mu \mathrm{gm}^{-3}\right)$ by compound categories in YD and non-YD periods $(n=26)$.

\begin{tabular}{|c|c|c|c|c|c|c|c|c|c|c|}
\hline & $\begin{array}{c}\mathrm{PM}_{10} \\
\left(\mu \mathrm{gm}^{-3}\right)\end{array}$ & $\begin{array}{l}\mathrm{RM} \\
(\%)\end{array}$ & $\begin{array}{c}\mathrm{OM} \\
+\mathrm{EC} \\
(\%)\end{array}$ & $\begin{array}{l}\text { Ions } \\
(\%)\end{array}$ & $\begin{array}{c}E \\
(\%)\end{array}$ & $\begin{array}{c}\mathrm{PM}_{2.5} \\
\left(\mu \mathrm{gm}^{-3}\right)\end{array}$ & $\begin{array}{l}\text { RM } \\
(\%)\end{array}$ & $\begin{array}{r}\mathrm{OM} \\
+\mathrm{EC} \\
(\%)\end{array}$ & $\begin{array}{l}\text { Ions } \\
(\%)\end{array}$ & $\begin{array}{c}\mathrm{E} \\
(\%)\end{array}$ \\
\hline $4 / 12 / 01 \mathrm{~d}^{\$}$ & 197 & 58 & 4 & 21 & 33 & 50 & 68 & 11 & 26 & 30 \\
\hline $4 / 12 / 0 \ln ^{s}$ & 150 & 48 & 5 & 22 & 21 & 42 & 79 & 11 & 34 & 34 \\
\hline $4 / 13 / 01 d^{5}$ & 129 & 71 & 5 & 25 & 41 & 38 & 90 & 12 & 37 & 41 \\
\hline $4 / 13 / 01 n^{s}$ & 74 & 71 & 14 & 28 & 29 & 32 & 102 & 33 & 41 & 28 \\
\hline $4 / 14 / 01^{8}$ & 116 & 66 & 9 & 30 & 27 & 45 & 77 & 17 & 42 & 18 \\
\hline April $\mathrm{YD}^{*}$ avg. & 133 & 63 & 7 & 25 & 30 & 41 & 83 & 17 & 36 & 30 \\
\hline $5 / 02 / 01 n^{\$}$ & 114 & 69 & 10 & 40 & 20 & 56 & 91 & 17 & 56 & 18 \\
\hline $5 / 03 / 01 d^{s}$ & 93 & 68 & 11 & 32 & 26 & 43 & 98 & 20 & 48 & 30 \\
\hline May YDªvg. & 103 & 69 & 10 & 36 & 23 & 49 & 94 & 18 & 52 & 24 \\
\hline Non-YD* avg. & 49 & 72 & 15 & 39 & 18 & 25 & 91 & 23 & 46 & 22 \\
\hline April $Y D^{*}$ avg./Non-YD ${ }^{*}$ avg. ${ }^{(\mathbb{*})}$ & 271 & 88 & 47 & 64 & 167 & 164 & 91 & 74 & 78 & 136 \\
\hline May YD* avg./Non-YD* avg. & 210 & 96 & 67 & 92 & 128 & 196 & 103 & 78 & 113 & 109 \\
\hline
\end{tabular}

The notations of *, \$, and @ are the same as Table 1.

$\mathrm{RM}(\%)$ is the reconstructed mass in percentage.

$\mathrm{OM}+\mathrm{EC}(\%)$ indicates the reconstructed mass in percentage for organic matter and elemental carbon.

Ions (\%) represent the reconstructed mass in percentage for the sum of watersoluble ions.

$\mathrm{E}(\%)$ denotes the reconstructed mass in percentage for the sum of elemental oxides.

The average mass concentrations of $\mathrm{PM}_{10}$ were 133, 103, and $49 \mu \mathrm{gm}^{-3}$ for April YD, May YD, and non-YD periods, respectively. In contrast, $\mathrm{PM}_{25}$ averages for April YD, May $\mathrm{YD}$, and non-YD periods were 41, 49, and $25 \mu \mathrm{gm}^{-3}$, respectively. From the comparisons of aerosol mass concentration between YD and non-YD periods, we find an enhancement of 110 and $171 \%$ in $\mathrm{PM}_{10}$ and 64 and $96 \%$ in $\mathrm{PM}_{2.5}$ for the two YD events. For all water-soluble ions, enhancements in terms of mass concentrations can be clearly seen in the YD periods. However, the enhancement of mass fraction for each species might be varied due to source contributions and atmospheric reactions. For example, $\mathrm{NH}_{4}{ }^{+}$and $\mathrm{SO}_{4}{ }^{2-}$ are major ions 


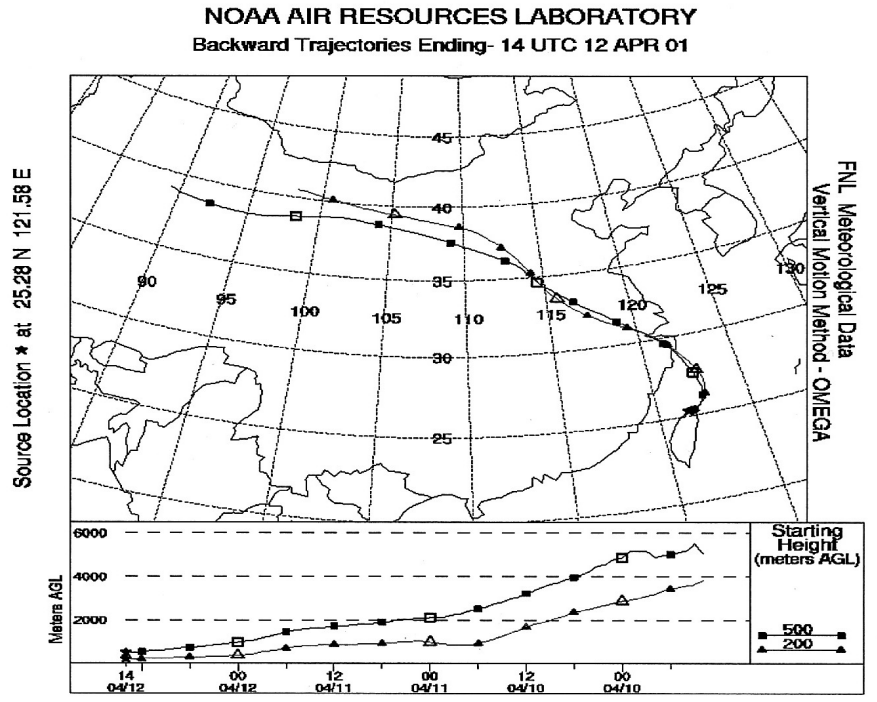

Fig. 3. The 72-hour back-trajectory calculated from HYSPLIT for the night of April 12, 2001 (Draxler 1999).

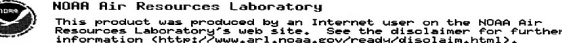

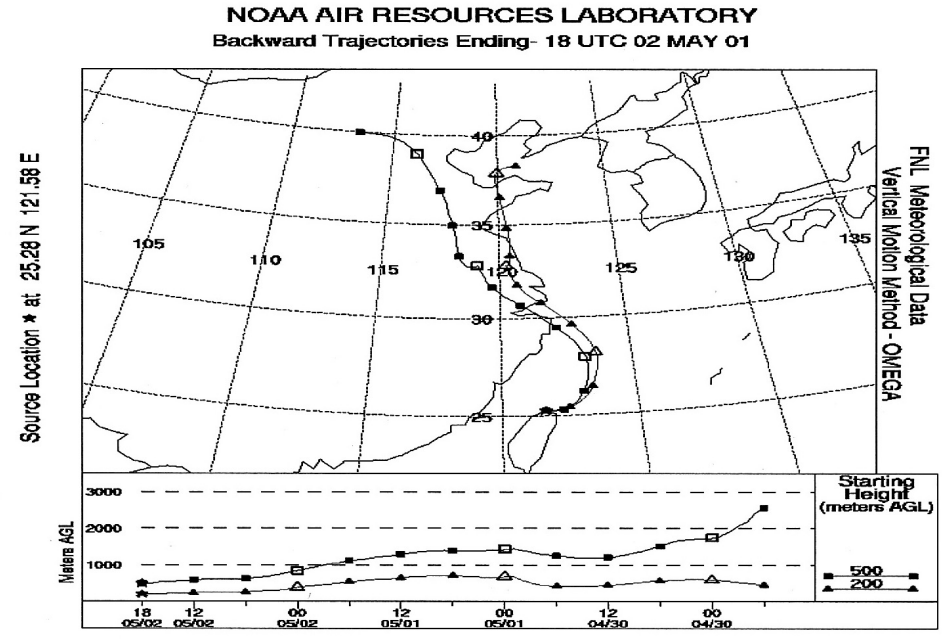

Fig. 4. The 72-hour back-trajectory calculated from HYSPLIT in the early morning of May 3, 2001 (Draxler 1999). 
produced from anthropogenic precursor gases; their enhancements indicate a significant longrange transport of air pollutants from the Asian Continent to the site.

A back-trajectory analysis showed that the April YD airflow came from the Gobi Desert in China via a relatively un-polluted inland route, while May YD airflow transported along the industrial coastal areas in China. This distinction in the transport path between the April and May dust events may well account for the difference in aerosol compositions of the two events.

Acknowledgements In this work, we appreciate the convenience of using the on-line HYSPLIT model developed from US NOAA Air Resources Laboratory. We would also like to acknowledge the financial support from ACE-Taiwan project NSC- 89-2111-M-002-036 funded by National Science Council, R.O.C.. This research is a contribution to the International Global Atmospheric Chemistry (IGAC) Core Project of the International Geosphere Biosphere Program (IGBP) and is part of the IGAC Aerosol Characterization Experiments (ACE).

\section{REFERENCES}

Draxler, R. R., 1999: Hybrid single-particle lagrangian integrated trajectories (HYSPLIT): Version 4.0- User's Guide. NOAA Technical Memorandum ERL ARL-230, Air Resources Laboratory, Silver Spring, MD, USA.

Duce, R. A., C. K. Unni, B. J. Ray, J. M., Prospero, and J. T. Merrill, 1980: Long-range atmospheric transport of soil dust from Asia to the tropical North Pacific: temporal variability. Science, 209, 1522-1524.

Fung, K., 1990: Particulate carbon speciation by $\mathrm{MnO}_{2}$ oxidation. Aerosol Sci. Technol., 12, 122-127.

Lin, T. H., 2001: Long-range transport of YD to Taiwan in Spring 2000: observed evidence and simulation. Atmos. Environ., 35, 5873-5882.

Mueller, P. K., K. K. Fung, S. L. Heisler, D. Grosjean, and G. M. Hidy, 1982: Atmospheric particulate carbon observations in urban and rural areas of the United States. In: Wolff, G. T., and R. L. Klimisch (Eds.), Particulate Carbon: Atmospheric Life Cycle, Plenum Press, New York, USA, 343-370.

Ohta, S., and T. Okita, 1990: A chemical characterization of atmospheric aerosol in Sapporo. Atmos. Environ., 24A, 815-822.

Parrington, J. R., W. H. Zoller, and N. K. Aras, 1983: Asia dust: seasonal transport to Hawaii Islands. Science, 220, 195-197.

Turpin, B. J., P. Saxena, G. Allen, O. Koutrakis, P. McMurry, and L. Hildemann, 1997: Characterization of the southwest desert aerosol, Meadview, AZ. J. Air Waste Manage. Assoc., 47, 344-356.

Xiao, H., G. R. Carmichael, J. Durchenwald, D. Thornton, and A. Bandy, 1997: Long-range transport of SOx and dust in East Asia during the PEM B Experiment. J. Geophys. Res., 102, 28589-28612.

Zhang, D. E., 1984: Synoptic-climate studies of dust fall in China since historic times.Zhongguo Кехие Вао, XXVII, 825-836. 